\title{
Método AVI (Aquifer Vulnerability Index) para a classificação da vulnerabilidade das águas subterrâneas na região de Campos dos Goytacazes, Rio de Janeiro
}

\author{
AVI method (Aquifer Vulnerability Index) for groundwater vulnerability \\ classification in Campos dos Goytacazes region, Rio de Janeiro, Brazil
}

\section{Marinaldo Gomes dos Santos}

Engenheiro Agrimensor. Mestre em Geociências pela Universidade Estadual de Campinas (Unicamp). Pós-graduado em Geociências pelo Departamento de Geologia e Recursos Naturais do Instituto de Geociências da Unicamp

\section{Sueli Yoshinaga Pereira}

Geóloga. Doutora em Ciências pela Universidade de São Paulo (USP). Professora do Departamento de Geologia e Recursos Naturais do Instituto de Geociências da Unicamp

\section{Resumo}

O presente artigo apresenta estudos para a classificação da vulnerabilidade à contaminação das águas subterrâneas na região de Campos dos Goytacazes, Rio de Janeiro. O método AVI (Aquifer Vulnerability Index) foi aplicado, utilizando-se o ferramental do Sistema de Informação Geográfica. O método AVI aplica o conceito de resistência hidráulica, dada pela somatória das taxas de espessura da zona não saturada pelas condutividades hidráulicas do meio. Os mapas resultantes mostraram que a região possui sensibilidade à contaminação das águas subterrâneas, com classificações que variam de "Alta" a "Extremamente alta" (0-10 dias a 10-100 dias, respectivamente). Essa sensibilidade elevada ocorre pela existência de formações de elevada permeabilidade (areias) e níveis de água rasos, típicas ocorrências do delta do rio Paraíba do Sul. O índice vulnerabilidade Alta ocorre: (1) nas margens direita e esquerda do rio Paraíba do Sul, (2) oeste da área (região de confluência do rio Muriaé com o rio Paraíba do Sul), e (3) parte leste da área urbana de Campos dos Goytacazes. Os terrenos com índice de vulnerabilidade Extremamente alta estão localizados: (1) na porção norte (área do Aquífero Barreiras), (2) na área urbana de Campos dos Goytacazes e dos distritos de Saturnino Braga e Mucurepe, (3) porção leste da área, (4) em terreno entre o canal de Cambaíba e o canal de Andreza, e (5) na porção sul da área (Lagoa Feia). Os resultados mostram a caracterização de um importante parâmetro ambiental da região, pretendendo subsidiar políticas públicas para preservação, proteção e uso racional desse importante manancial subterrâneo.

Palavras-chave: vulnerabilidade de águas subterrâneas; aquíferos; Aquifer Vulnerability Index (AVI); Campos dos Goytacazes; Sistema de Informação Geográfica.

\begin{abstract}
The present paper shows studies aiming groundwater vulnerability evaluation in Campos dos Goytacazes region, Rio de Janeiro, Brazil. The Aquifer Vulnerability Index (AVI) was the vulnerability method applied, using Geographical Information System tools. The AVI Method has adopted the concept of hydraulic resistivity (sum of taxes among unsaturated thickness and hydraulic conductivity). Result maps showed that the region has groundwater vulnerability to contamination from high to extreme levels. The vulnerability varied from "High" to "Extremely high" indexes (from 0-10 days to 10-100 days, respectively). This high vulnerability was attributed to the occurrence of high permeability formations (sands) and shallow water table, typical from the delta of Paraíba do Sul river. High vulnerability index terrains are situated in the following areas: (1) along the right and left banks of Paraíba do Sul river, (2) in the west side of the study area (region of Muriaé and Paraíba do Sul rivers confluence), and (3) in the east side of urban area of Campos dos Goytacazes. The Extremely high index areas are located: (1) in the north portion (Barreiras aquifer), (2) in urban area of Campos dos Goytacazes, besides Saturnino Braga and Mucurepe districts, (3) eastern region of the studied area, (4) in a portion area between Cambaíba and Andreza water drainage channels, and (5) in terrains situated in the south portion of the area (Feia lake). These results showed an important environmental parameter in the river delta region, intending to subsidized public policies to preserve, to protect, and to sustain this important groundwater resource.
\end{abstract}

Keywords: groundwater vulnerability; aquifers; Aquifer Vulnerability Index (AVI); Campos dos Goytacazes; Geographical Information System. 


\section{Introdução}

A região de Campos dos Goytacazes situa-se no delta do Rio Paraíba do Sul e caracteriza-se pela grande disponibilidade de recursos hídricos superficiais (SILVA, 1987). Caetano (2000) identificou também reservas imensas de água subterrânea e denominou os aquíferos como Aquífero Barreiras, Aquífero Quaternário Deltaico e Aquífero Emborê. Somente no Quaternário Deltaico existe uma reserva total de 11,7 bilhões de metros cúbicos e reserva renovável de 15,5 milhões de metros cúbicos. No entanto, sérios problemas ambientais já foram identificados, devido ao histórico do uso e ocupação do solo no município, caracterizado por assentamentos urbanos sem rede de esgoto sanitário, disseminação de lixões, disposição de resíduos das usinas de açúcar e álcool e a salinização do solo (FREITAS, 2003).

Assim, o mapeamento da vulnerabilidade aqui apresentado avaliou o grau de suscetibilidade à contaminação existente na região de Campos dos Goytacazes. O método AVI (Aquifer Vulnerability Index) (VAN STEMPVOORT et al. 1992) foi desenvolvido pelo Instituto Nacional de Pesquisa Hidrológica do Canadá (NHRI) e aplicado no presente trabalho, tendo como plataforma o Sistema de Informações Geográficas (SIG) e como fonte de informações os dados disponíveis do PROJIR (1983).

Esse método foi escolhido em função dos dados quantitativos disponíveis na área de estudo, simplicidade de utilização e de entendimento e sua fácil aplicação local. O parâmetro resistividade hidráulica pôde ser calculado, uma vez que havia muitas informações sobre a espessura da zona não saturada e valores de condutividade hidráulica (K) por toda a área de estudo.

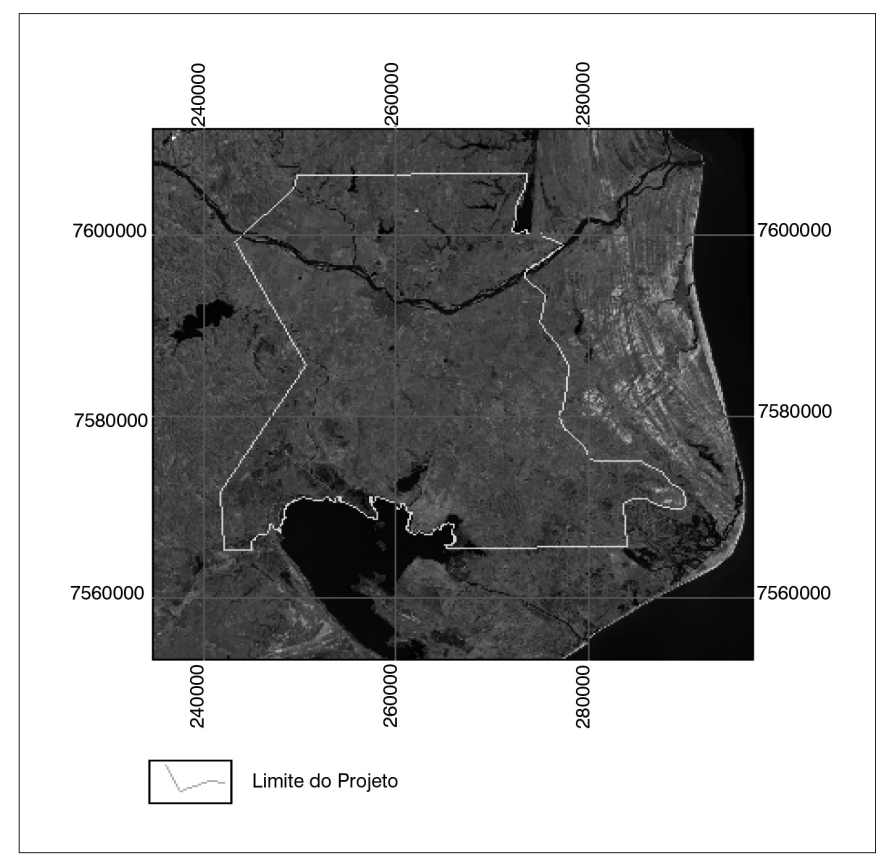

Figura 1 - Imagem do sensor ETM + do satélite Landsat 7 com 0 limite da área de estudo.
O conceito de vulnerabilidade adotado neste trabalho é definido por Foster e Hirata (1988) como "a susceptibilidade de um determinado aqüífero ou manancial em ser degradado por certa atividade antrópica".

Uma área de $1.248 \mathrm{~km}^{2}$ foi definida pelo perímetro de $202 \mathrm{~km}$ na imagem do sensor ETM+ do satélite Landsat 7 (Figura 1), na baixada do município de Campos dos Goytacazes, região norte do estado do Rio de Janeiro. A área dista da capital cerca de 280 km, e sua principal via de acesso é a rodovia federal BR 101. A área de estudo compreende a parte sedimentar do município, onde se situam as principais áreas urbanizadas e as atividades de cana-de-açúcar. Os limites da área de estudo compreendem ao sul o limite do município de Campos e a Lagoa Feia; a leste, a delimitação do município de Campos; ao norte, os limites do PROJIR (1983) e a oeste, os limites dos aquíferos Quaternário Deltaico e Barreiras (CAETANO, 2000).

\section{Aspectos fisiográficos}

De acordo com CIDE (1997), o Município de Campos dos Goytacazes localiza-se na porção continental da Bacia Sedimentar de Campos, apresentando três unidades geomorfológicas: (1) colinas e maciços costeiros formados por rochas de idade pré-cambriana; (2) os tabuleiros costeiros produzidos por depósitos sedimentares com origem no Cenozoico, a partir do Terciário Superior; e (3) a planície costeira, de idade quaternária, formada em ambientes de sedimentações fluvial, lacustre e marinha, sofrendo grande influência deltaica do rio Paraíba do Sul.

$\mathrm{Na}$ formação Barreiras ocorre o Argissolo Amarelo. Ao longo das planícies litorâneas, são identificados os solos podzol hidromórfico. Os solos glei e de aluviões (argilo-siltosos) ocorrem nas várzeas dos principais rios, como no delta do rio Paraíba do Sul. Por fim, na área são encontrados os solos salino-sódicos (halomórficos e solonchak sódico).

O clima, tipicamente tropical, foi classificado como quente (temperaturas acima de $18^{\circ} \mathrm{C}$ ) e semiúmido (4 a 6 meses secos) e seco ( 7 a 10 meses secos). A umidade relativa média atinge valores pouco acima de $80 \%$ na faixa litorânea, entre 70 e 80\% na área em estudo e, na região interiorana, chega a assumir valores inferiores a $65 \%$ (CIDE, 1997). A precipitação anual na área do projeto varia entre 800 e $1.200 \mathrm{~mm}$, com uma tendência de incremento dessa pluviosidade a partir do litoral para o interior, concentrando-se entre os meses de outubro e abril cerca de $80 \%$ do total anual. O trimestre menos chuvoso é o de junho-julho-agosto.

Em relação à hidrografia, a margem esquerda do rio Paraíba do Sul é formada por diversas lagoas, os rios Muriaé e Morto, além de diversas áreas de inundação. Na margem direita, encontra-se rede de canais de drenagem construída pelo extinto Departamento Nacional de Obras e Saneamento (DNOS) na década de 1940, com funções de irrigação, drenagem e saneamento. Os canais principais são 
Macaé-Campos, Coqueiro, São Nicolau, Tocos, Cambaíba e Andreza. Existem ainda as lagoas Jacaré e Feia, esta última considerada a maior lagoa de água doce do Brasil.

Os valores das vazões do rio Paraíba do Sul, medidos no posto fluviométrico da Ponte Municipal em Campos, demonstram que a média das vazões máximas é de 3.357,11 m³/s, a média das mínimas é de $331,26 \mathrm{~m}^{3} / \mathrm{s}$, e a média das médias equivale a $875,97 \mathrm{~m}^{3} / \mathrm{s}$ (PROJIR, 1983).

\section{Contexto geológico e hidrogeológico}

A área de estudo situa-se na parte emersa da bacia sedimentar de Campos, que é delimitada ao norte pelo Arco de Vitória, que a separa da Bacia do Espírito Santo, e ao sul pelo Arco de Cabo Frio, que a separa da Bacia de Santos. A Bacia de Campos é uma bacia de idade mesozoica-cenozoica da margem continental brasileira, onde se apresentam dois sistemas semitransversais (NE-SW e NW-SE) de alinhamentos regionais na bacia que originaram uma alternância de horsts e grabens. Estudos geológicos sobre a formação e evolução da bacia foram realizados, destacando-se, dentre outros, os trabalhos de Lamego (1955), Gama Jr. (1977) e Martin et al. (1997). A bacia, no geral, contém sedimentos quaternários, em aluviões de várzea e aluviões flúvio-marinhos, e os tabuleiros de sedimentos de idade Terciária da Formação Barreiras. A Formação Barreiras é composta de sedimentos depositados em ambiente lacustre - com textura argilo-siltosa e areno-argilosa - e fluvial, constituídos de areias e conglomerados argilosos (PROJIR, 1983). As aluviões, de idade Quaternária e pertencentes às planícies costeiras, foram depositadas sobre sedimentos da Formação Barreiras e outros de origem marinha. Elas são compostas de sedimentos com até $30 \mathrm{~m}$ de espessura e possuem 2 padrões de sedimentação: (1) flúvio-marinho, que ocupa 2/3 da planície, com grande variação vertical e lateral de texturas. Argilas, siltes, areias e matéria orgânica ocorrem em forma de lentes pouco espessas e de pequenas extensões, isoladamente ou nas mais diversas proporções; (2) marinho-litorâneo, disposto em duas camadas - a superior, de areias finas com diversas granulometrias, e a inferior, de argilas e siltes argilo-arenosos.

$\mathrm{Na}$ área de estudo, ocorrem os sedimentos dos depósitos quaternários, principalmente na sua porção central. A Formação Barreiras, ao norte, ocorre na margem esquerda do rio Paraíba do Sul e na parte sudeste. Os depósitos arenosos quaternários ocorrem a leste e sudeste e apresentam superfície retrabalhada pelo vento e dunas estabilizadas; já na porção mais ao sul, são encontrados sedimentos indiferenciados de lagos e pântanos (argilas ricas com matéria orgânica) próximos à Lagoa Feia e sedimentos arenosos de idade Quaternária mais antiga. A área apresenta várias estruturas e sedimentos indicativos de paleocanais, meandros abandonados resultantes da movimentação do canal principal do rio ao longo do tempo.
De acordo com Caetano (2000), o município de Campos dos Goytacazes dispõe do sistema aquífero fraturado (oeste do município), com baixo potencial, com capacidade específica variando de 0,02 a $1,53 \mathrm{~m}^{3} / \mathrm{h} / \mathrm{m}$ e valores médios de vazão de $5,73 \mathrm{~m}^{3} / \mathrm{h}$. Os aquíferos sedimentares apresentam as seguintes características: Aquífero Formação Barreiras, de não confinado a confinado pelos sedimentos quaternários, constituídos de sedimentos clásticos continentais indiferenciados, com valores de transmissividade médios entre 110,18 e 222,52 m²/dia, produtividade média de 1,09 a 2,45 $\mathrm{m}^{3} / \mathrm{h} / \mathrm{m}$ e valores médios de vazão entre 34,55 e $47,17 \mathrm{~m}^{3} / \mathrm{h}$; o Aquífero Emborê, também de idade Terciária, confinado, constituise de intercalações de arenito e folhelho (ou argilito), com caráter multi-camada, transmissividade de 191,40 m²/dia, produtividade em torno de $3,5 \mathrm{~m}^{3} / \mathrm{h} / \mathrm{m}$ e vazão média de $70,93 \mathrm{~m}^{3} / \mathrm{h}$, e o Aquífero Quaternário Deltaico, de caráter livre, formado por solos residuais, areias, cascalhos, argilas e siltes, atingindo até $120 \mathrm{~m}$ de espessura, elevada transmissividade média $\left(8.193,00 \mathrm{~m}^{2} / \mathrm{dia}\right)$ e vazão média de $139,67 \mathrm{~m}^{3} / \mathrm{h}$

A Figura 2 apresenta o mapa de delimitação dos aquíferos e seção hidrogeológica, de acordo com Caetano (2000), e a configuração da área de estudo. O perfil L-L' apresenta a variação das espessuras dos aquíferos sedimentares pela ocorrência de falhamentos (grábens e horsts) no embasamento cristalino.

A área de estudo abrange principalmente o Aquífero Quaternário Deltaico em sua porção central, com grande espessura devido ao rebaixamento de blocos estruturais que permitiu o preenchimento de sedimentos fluviais quaternários; os aquíferos de idade Terciária localizam-se ao norte da área (Aquífero Barreiras) e ao sul, com o Aquífero Emborê, cobertos pelos sedimentos quaternários. O fluxo da água subterrânea na área de estudo foi elaborado por meio dos dados provenientes da campanha piezométrica do projeto de irrigação e drenagem da cana-de-açúcar na região Norte-Fluminense (PROJIR, 1983) e comparado com a elaborado por Freitas (2003). As duas campanhas, com momentos diferentes, indicaram a viabilidade de utilização dos dados de 1983, uma vez que não houve a verificação de grandes diferenças entre elas.

O mapa potenciométrico (Figura 3) indica as direções de fluxo de água subterrânea. As maiores cargas hidráulicas situam-se na porção noroeste da área e as menores, na porção sudeste, indicando um fluxo geral de sentido noroeste-sudeste. O rio Paraíba do Sul é influente-efluente, sendo que, na margem esquerda, recebe águas do Aquífero Barreiras e do embasamento cristalino; no entanto, na margem direita, as águas do rio alimentam o aquífero subjacente. Por sua vez, as águas desse aquífero apresentam fluxo principal na direção sul e sudeste, descarregando na lagoa Feia e no oceano. Há uma contribuição das águas do aquífero cristalino na porção oeste da área.

Os canais de drenagem existentes são efluentes, ou seja, o aquífero descarrega água subterrânea nesses canais, como se deveria esperar, uma vez que foram construídos como drenos. 

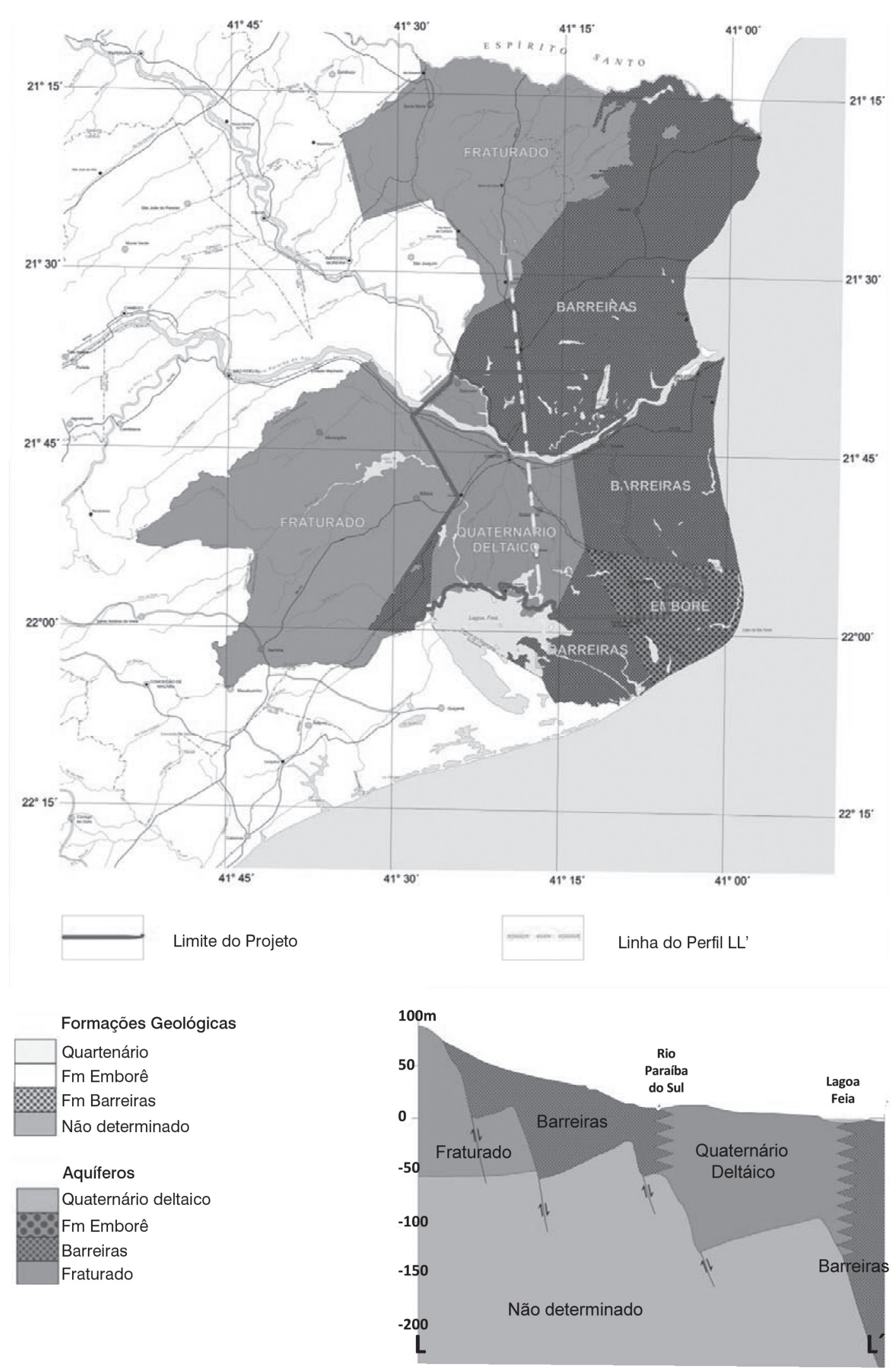

Fonte: Caetano (2000).

Figura 2 - Delimitação dos aquíferos da região de Campos. Fm: formação. 


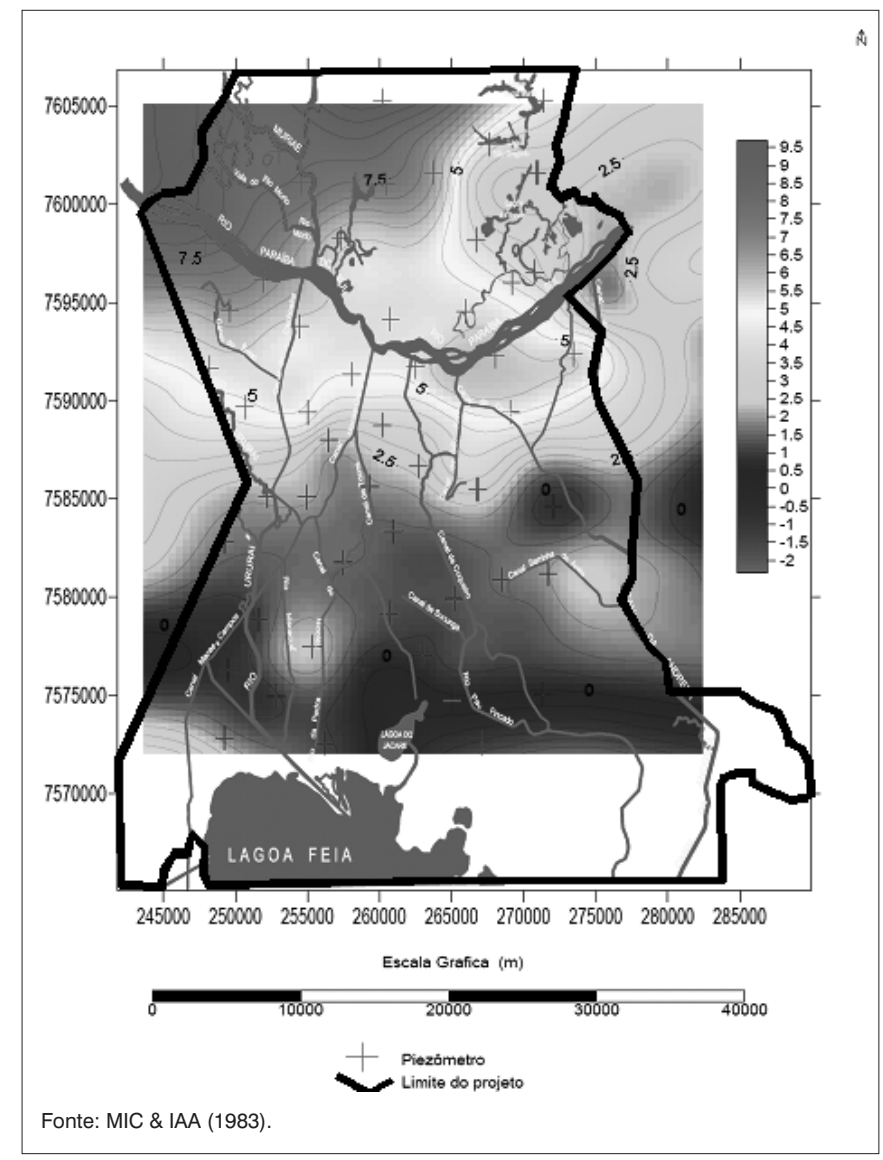

Figura 3 - Mapa da superfície potenciométrica da área de estudo.

\section{Materiais e Métodos}

Vários materiais e métodos foram utilizados para a caracterização da vulnerabilidade dos aquíferos. Estes estudos envolveram técnicas de processamento de dados, modelos digitais de terreno, sensoriamento remoto e campanha de campo, utilizando-se de várias cartas, mapas, imagens, dados censitários e hidrogeológicos. Os principais softwares utilizados foram o IDRISI versão 3.2, ENVI 3.6, ER-MAPPER 6.2 e PANA VUE 2.0. Os procedimentos de estudos consistiram na realização de um levantamento preliminar dos documentos (dados, mapas e trabalhos técnicos e científicos) já existentes na área, trabalhos de campo, tratamento e interpretação das informações.

\section{Levantamento de informações sobre a área}

As principais fontes de dados são do projeto de irrigação e drenagem da cana-de-açúcar na região Norte-Fluminense (PROJIR, 1983), o qual abrangeu as áreas de Climatologia, Hidrologia, Geologia, Pedologia, Hidrogeologia, Geotecnia, SócioEconomia e Agronomia. Os estudos hidrogeológicos recentes (CAETANO, 2000; FREITAS, 2003) e o cadastramento dos poços também definiram o modelo de circulação e a descrição hidrodinâmica dos sistemas aquíferos necessários para caracterização da vulnerabilidade.
Os materiais utilizados no projeto foram os dados da campanha piezométrica de 1983 (PROJIR, 1983).

As bases cartográficas foram aquelas elaboradas pelo IBGE na escala 1:50.000 de 1968, compreendendo as folhas de Travessão, Campos, São João da Barra e Muçurepe. Os demais mapas e imagens identificadas para o uso no presente projeto foram:

- mapa geológico do estado do Rio de Janeiro escala 1:400.000 (FONSECA, 1998) utilizado apenas para reconhecer a geologia regional da área, não entrando no processamento dos dados;

- $\quad$ imagem do sensor ETM+ do satélite Landsat 7 de fevereiro de 2003;

- mapa das condutividades hidráulicas escala 1:25.000 (PROJIR, 1983);

- mapa das profundidades do nível freático escala 1:25.000 (PROJIR, 1983).

\section{Etapa de campo}

O conjunto de operações de campo visou levantar os dados das fontes potenciais de poluição, inclusive com a visita e identificação de algumas destas por meio do sistema de posicionamento global (GPS), utilizando-se, para isso, um receptor portátil GARMIN modelo ETREX. Além disso, realizou-se complementação da base cartográfica da área em estudo no acervo do projeto PROJIR (1983) e pesquisa de material bibliográfico na Universidade Federal Rural do Rio de Janeiro, Campus Dr. Leonel Miranda.

\section{Tratamento dos dados}

O software Idrisi 3.2 foi utilizado para elaborar os mapas intermediários (modelos de elevação) e os finais, devido ao fato de o mesmo ter grande capacidade para trabalhar com dados no formato raster (EASTMAN, 1995). O software Surfer 8 foi empregado para geração das superfícies contínuas e de contorno do modelo potenciométrico; o ENVI versão 3.6 foi empregado para classificação da imagem do sensor ETM+ do satélite Landsat 7 e o ER-Mapper versão 6.2, para correção geométrica e georreferenciamento dessa imagem. O AUTO CAD Map 2000 e o R2V foram utilizados para as vetorizações das cartas e da imagem de satélite.

As superfícies contínuas, juntamente com as cartas, mapas e imagens, foram combinadas e transformadas em novos mapas, utilizando-se as ferramentas e operações do Idrisi 3.2.

As nove cartas de profundidades do nível freático que recobre a área de estudo foram digitalizadas e georreferenciadas, cujo mapa resultante gerou uma base digital, a qual foi exportada para o software Idrisi, versão 3.2. O mapa de profundidades $(\Sigma \mathrm{d})$ foi produzido por meio de técnicas de análise espacial, dentre as quais está a modelagem de dados por meio do interpolador TIN.

Seguindo-se os mesmos passos para a confecção do mapa das profundidades do nível freático, as nove cartas de condutividades hidráulicas do PROJIR (1983) foram transformadas no mapa das condutividades ( $\Sigma K)$. 
Por meio do software Idrisi versão 3.2, o modelo AVI foi elaborado por meio da utilização da álgebra de mapas com a operação de divisão entre os mapas de profundidades $(\Sigma \mathrm{d})$ e condutividades $(\Sigma \mathrm{K})$. Dessa operação, gerou-se o mapa das resistências hidráulicas, as quais foram reclassificadas em faixas de acordo com o método AVI e, após alguns acabamentos cartográficos, chegou-se ao mapa de vulnerabilidade.

Os mapas principais e intermediários gerados foram:

- mapa de vulnerabilidade

- mapa de condutividades hidráulicas;

- mapa das profundidades do nível freático.

\section{Método AVI}

O mapa de vulnerabilidade à contaminação das águas subterrâneas da área estudada foi desenvolvido a partir do método AVI, desenvolvido pelo NHRI. Esse método foi escolhido em função dos dados disponíveis pelo PROJIR (1983), pela simplicidade de utilização e pela fácil aplicação para o local em estudo.

Esse método é baseado em dois parâmetros físicos:

- espessura (d) de cada camada sedimentar acima da parte saturada do aquífero;

- condutividade hidráulica de cada uma dessas camadas sedimentares $(\mathrm{K})$.

Com base nesses dois parâmetros, d e K, a resistência hidráulica (C) é calculada pela Equação 1:

$\mathrm{C}=\Sigma \mathrm{di} / \mathrm{ki}$ para camadas de $1 \mathrm{a}$ i. $[\mathrm{T}]$

Equação 1

Sendo que, pela variação de $C$, pode-se classificar a vulnerabilidade como sendo extremamente alta, alta, moderada, baixa e extremamente baixa (Tabela 1).

O mapa de vulnerabilidade foi gerado, conforme o fluxograma da Figura 4 (SANTOS, 2004).

Tabela 1 - Classificação da vulnerabilidade - AVI (VAN STEMPVOORT et al., 1992)

\begin{tabular}{lc} 
Resistência hidráulica (dias) & Classes de vulnerabilidade \\
$0-10$ & Extremamente alta \\
$10-100$ & Alta \\
$100-1.000$ & Moderada \\
\hline
\end{tabular}

Tabela 2 - Classes de condutividade hidráulica de acordo com dados do PROJIR (1983)

\begin{tabular}{lc}
\multicolumn{2}{c}{ Condutividade hidráulica } \\
\hline Classe & Valor (m/dia) \\
\hline Baixa & 0,07 \\
\hline Moderadamente baixa & 0,31 \\
Moderada & 1,00 \\
\hline Moderadamente alta & 2,25 \\
Alta & 3,75 \\
Muito alta & 5,00
\end{tabular}

\section{Resultados}

Na elaboração do mapa de vulnerabilidade, vários mapas intermediários foram criados, os quais serão descritos a seguir.

\section{Mapa de elevação das condutividades hidráulicas do nível freático}

O mapeamento da condutividade hidráulica dos solos para a região norte-fluminense na escala 1:25.000 foi realizado pelo PROJIR (1983). Os valores de condutividade hidráulica foram classificados em Baixa, Moderadamente baixa, Moderada, Moderadamente alta, Alta e Muito alta, de acordo com faixas de valores de resistência hidráulica, apresentadas na Tabela 2.

Para adequar os dados de condutividade hidráulica para a geração do modelo de elevação, foi adotada a classe com o menor valor, de acordo com Oliveira (2001), o qual comenta que a classe de drenagem de um solo é comandada pela permeabilidade do horizonte menos permeável.

Após as digitalizações das cartas, os valores de condutividade hidráulica foram incorporados às suas respectivas classes e exportados para o Idrisi versão 3.2, no qual se procedeu ao processamento com a aplicação do interpolador TIN para a geração do modelo de elevação (Figura 5).

$\mathrm{Na}$ área de estudo, percebem-se claramente os altos valores de condutividade hidráulica. As áreas mais condutivas hidraulicamente (entre 3,05 a 3,75 m/dia) ocorrem na porção leste da área de estudo. No geral, os valores mais baixos predominam, na maior parte, na margem direita do rio Paraíba do Sul (entre 0,00 a 0,70 m/dia). A Formação Barreiras aflorante (margem esquerda) apresenta condutividades moderadas (entre 0,94 a 1,41 m/dia). Na margem direita, os sedimentos atingem os valores mais elevados da área de estudo $(2,58$ a $3,75 \mathrm{~m} / \mathrm{dia})$.

\section{Modelo de elevação das profundidades do nível freático}

O projeto de irrigação e drenagem da cana-de-açúcar na região norte-fluminense (PROJIR, 1983), com o objetivo de analisar o comportamento do nível freático para o estudo dos problemas de drenagem, elaborou o mapeamento com o registro das profundidades do nível dessa região na escala 1:25.000. Os dados do registro do nível freático foram exportados para o SIG. No módulo de análise, e utilizando-se o interpolador TIN, os dados foram processados, gerando, assim, o modelo de elevação das profundidades (Figura 6).

As áreas com nível freático menos raso (entre 0,00 a 1,84 m) encontram-se nos limites norte, leste e sul da área, e as mais profundas (entre 2,76 a 3,07 m), na porção central e oeste da área. 


\section{Mapa de vulnerabilidade natural dos aquíferos de} Campos

O mapa foi elaborado por meio do SIG com o uso do software Idrisi 3.2. O método compreendeu a utilização da técnica de análise espacial da qual faz parte a álgebra de mapas; foi realizada a operação de divisão para os modelos de profundidade e condutividade, obtendo-se, assim, um mapa com os valores das resistências hidráulicas.
Esses valores foram reclassificados com um operador de contexto, conforme as faixas cabíveis que, no caso, foram de 0-10 e 10-100 dias. Assim, de acordo com a Tabela 1, obteve-se o mapa formado pela classe Extremamente alta e classe de Alta vulnerabilidade (Figura 7).

A Figura 7 apresenta a ocorrência da classe com vulnerabilidade alta em grande parte na área localizada na margem direita do rio Paraíba do Sul: a leste, onde está localizado o distrito de Poço Gordo, apresenta profundidade do nível freático variando de 1,0 a 2,0 m, condutividade
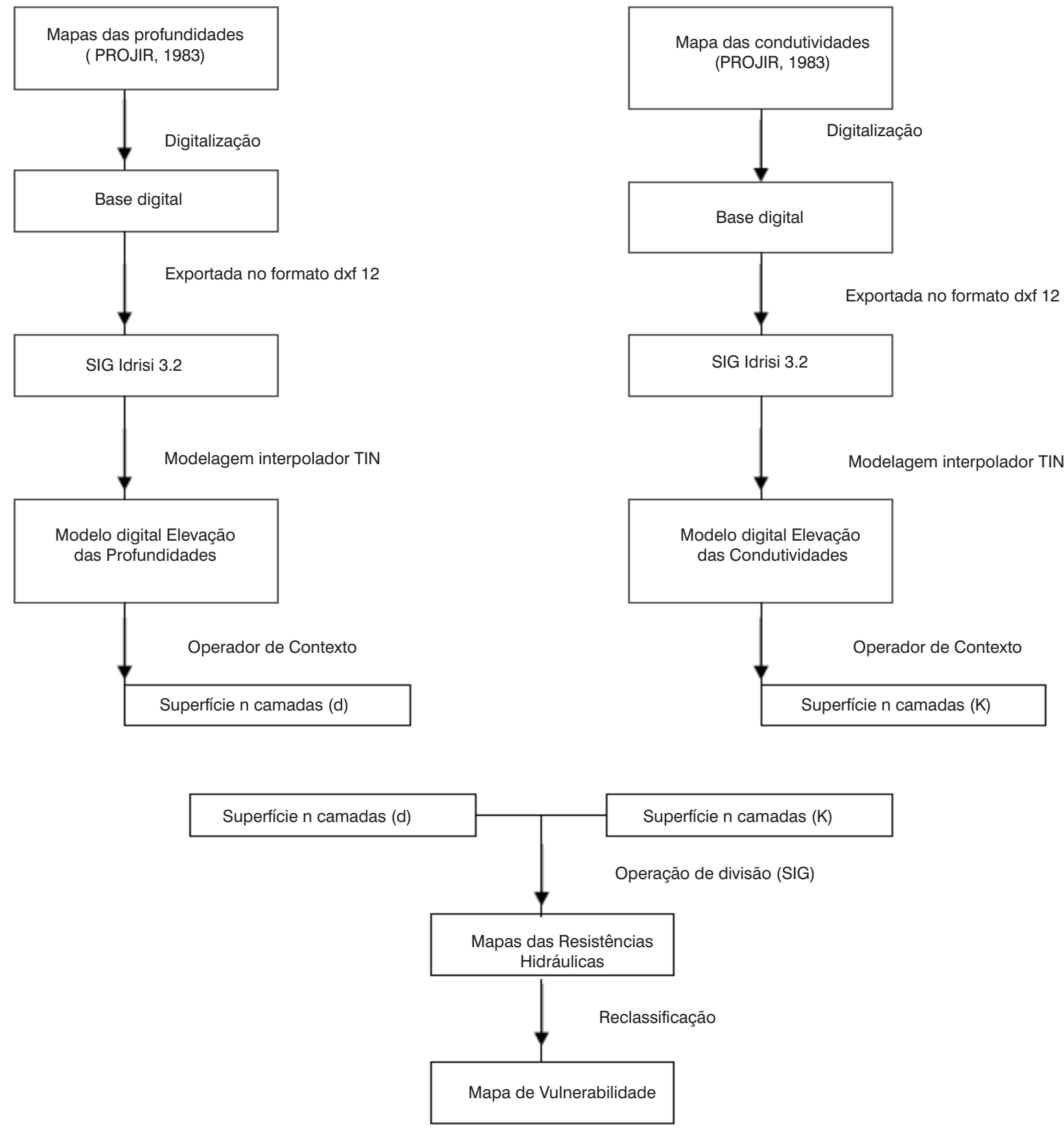

Figura 4 - Fluxograma de elaboração do mapa de vulnerabilidade em Sistema de Informação Geográfica da área de estudo (SANTOS, 2004). 


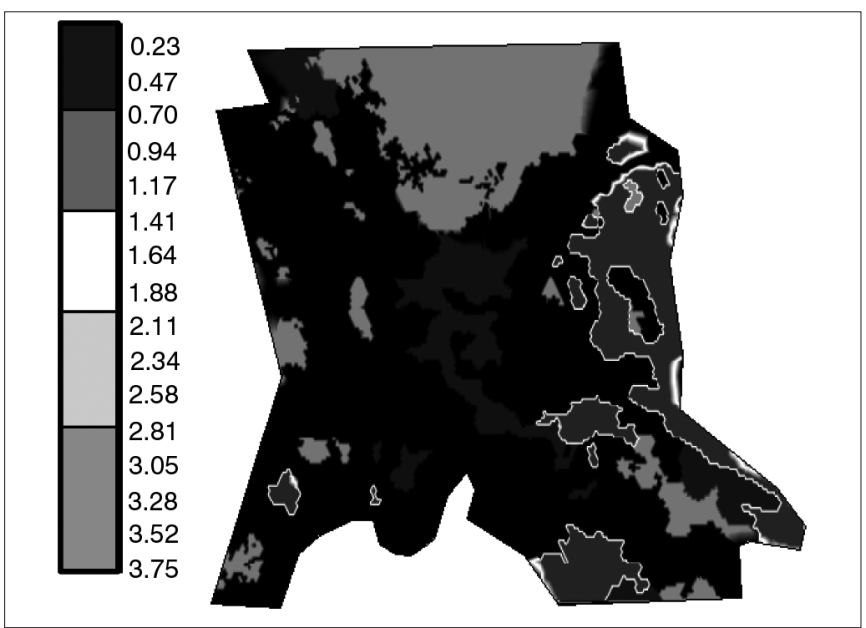

Figura 5 - Modelo de elevação dos valores das condutividades hidráulicas dos aquíferos (m/dia).

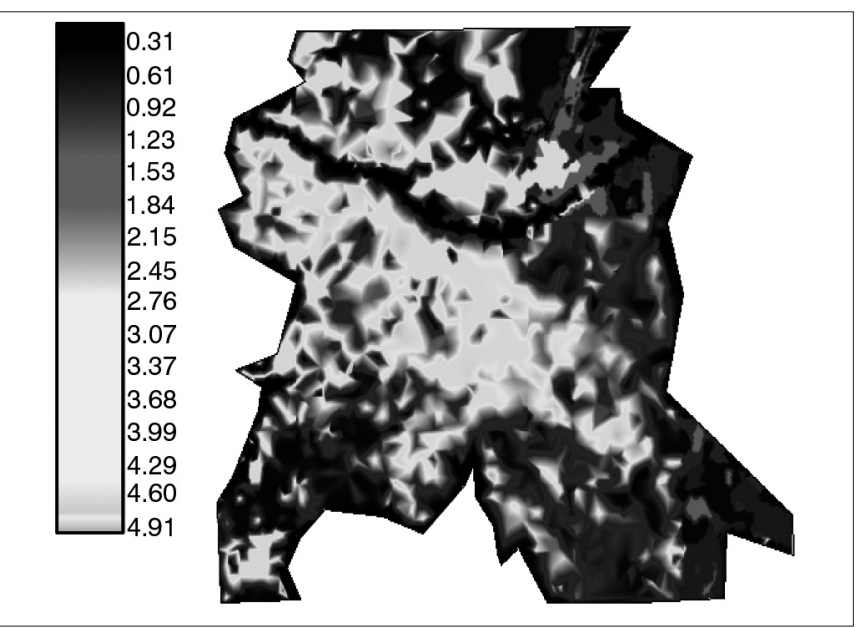

Figura 6 - Modelo de elevação dos valores de profundidade dos aquíferos (m).

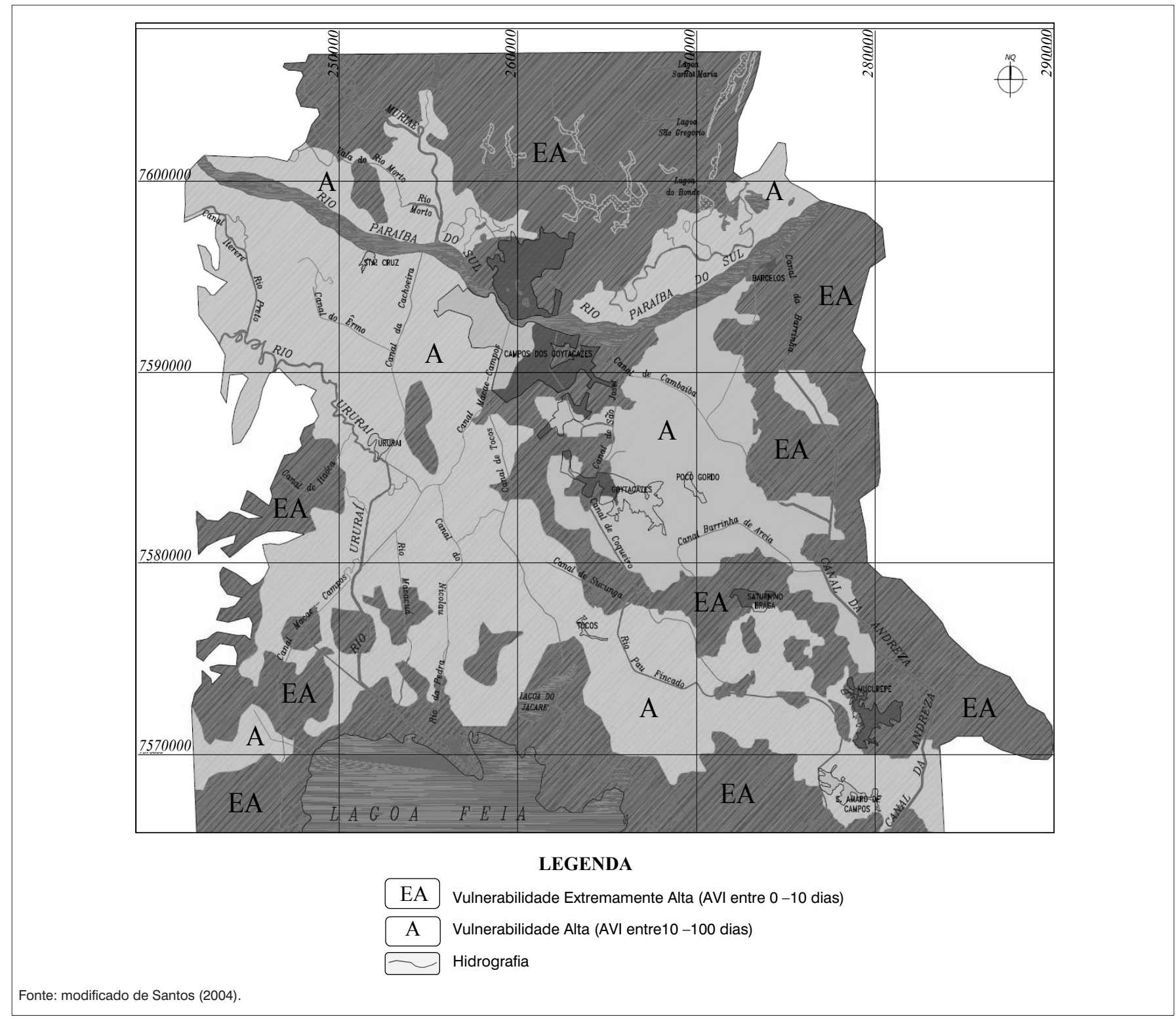

Figura 7 - Mapa de vulnerabilidade natural da região de Campos de Goytacazes, Rio de Janeiro. 
hidráulica em torno de 0,1 m/dia e predominância de solos areno-argilosos; e a oeste, em porção que compreende o rio Ururaí, o distrito de Tocos e Santo Amaro de Campos, limitado por áreas de vulnerabilidade extremamente alta. É compreendido exclusivamente pelo aquífero Quaternário Deltaico, com profundidade do nível freático em torno de 2,5 m e condutividade hidráulica de $0,2 \mathrm{~m} /$ dia, formada por solos mais argilosos. Na margem esquerda, ocorre também a classe de vulnerabilidade alta, na região de confluência do rio Muriaé com o rio Paraíba do Sul, e uma faixa que vai das proximidades da área urbana de Campos até o limite do projeto.

A ocorrência desse índice de vulnerabilidade está diretamente ligada aos valores de condutividade hidráulica moderadamente baixa e baixa, de acordo com o PROJIR (1983), e também às profundidades maiores do nível freático.

A classe de vulnerabilidade extremamente alta concentra-se basicamente na parte norte do projeto, na área do Aquífero Barreiras, com profundidades do nível freático variando de 0,9 a 2,5 m e condutividade hidráulica por volta de 1,0 m/dia, formado de solos mais arenosos e latossólicos. Além dessa, há a ocorrência de três faixas bem características com vulnerabilidade extremamente alta. A primeira delas é a que passa pela área urbana de Campos no sentido sudeste, passando pelos distritos de Saturnino Braga e Mucurepe; vale salientar que essa faixa está disposta em uma região de antigos paleocanais, com profundidades do nível freático em torno de 1,2 m e condutividade hidráulica por volta de $1 \mathrm{~m} /$ dia. Contornando a região da lagoa Feia, existe a outra área, com profundidades do nível freático em torno de 0,9 m e condutividade hidráulica entre 0,1 e 0,2 m/dia. Nessa área, predominam os solos com expressiva presença de matéria orgânica. A última faixa, na parte leste do mapa, compreende uma porção entre o canal de Cambaíba e o canal de Andreza; é uma área com profundidades de água subterrânea em torno de 0,8 m e de condutividade hidráulica por volta de 3,0 m, onde há o predomínio de solos arenosos.

Essa classe tem ocorrências influenciadas pelos valores de condutividade hidráulica, como, por exemplo, na parte norte da área do projeto, que possui valores de $1 \mathrm{~m} /$ dia, assim como também na parte leste, próximo ao canal de Cambaíba e Andreza (leste da área), com 3,0 m/dia. Essa classificação é atribuída também à pequena profundidade do nível freático, como ocorre na proximidade da lagoa Feia.

\section{Discussão e conclusões}

O ferramental do SIG foi utilizado devido à existência de um grande volume de informações envolvidas, um complexo nível de processamento de imagens e geração de diversos mapas temáticos. Esse sistema mostrou-se apropriado para trabalhos dessa envergadura, como também fornece bases digitais que podem ser atualizadas continuamente.

O método de vulnerabilidade adotado para este trabalho (AVI) apresentou-se adequado para a região, uma vez que esta possuía dados para cálculos de resistência hidráulica (condutividades hidráulicas e espessuras de camadas da zona não saturada). No trabalho, as variações das condutividades hidráulicas verticais não foram consideradas, pois não foram notadas variações verticais da zona não saturada, e a profundidade do nível de água é muito rasa.

No entanto, as três faixas de classificação das resistências hidráulicas do método proposto possuem grande abrangência, desconsiderando-se valores intermediários que podem ser significativos em determinados casos.

Coridola et al. (2005) apresentam para o município de Campos dos Goytacazes um mapa preliminar de vulnerabilidade dos aquíferos, utilizando-se o método GOD (FOSTER; HIRATA, 1988). As classes definidas variaram de baixa a extrema e, particularmente, na presente área de estudo, os índices variaram de moderada (na Formação Barreiras) a alta. O método DRASTIC (ALLER et al. 1987) também foi aplicado no município por Alves et al. (2009). Os índices obtidos foram de baixa a extrema por todo o município; na área de estudo, os índices determinados foram moderada (Formação Barreiras) e alta.

As áreas mapeadas com índice de vulnerabilidade alto são concordantes nos mapas que utilizaram as três metodologias e abrangem uma faixa que se estende do sentido noroeste a sudeste da área de estudo. No entanto, dentro dessa faixa, existem locais restritos com os índices de vulnerabilidade extremamente alta (métodos GOD e DRASTIC); porém, no mapa do método AVI, esse índice apresenta área contínua e maior.

As áreas situadas ao norte do rio Paraíba do Sul e às margens da Lagoa Feia apresentaram, no método GOD (CORIDOLA et al. 2005) e no método DRASTIC (ALVES et al. 2009), índices de vulnerabilidade moderada, enquanto que no método AVI o índice obtido foi extremamente alto.

A classificação do índice extremamente alto pelo método AVI nessas áreas citadas pode ser atribuída: (1) à existência de paleocanais com elevados valores de condutividade hidráulica (0,94 a 1,17 $\mathrm{m} /$ dia) em faixa de área que compreende o município de Campos e se prolonga entre os canais de Coqueiro e Tocos, o distrito de Saturnino Braga e Mucuripe; (2) na combinação dos valores elevados de condutividade hidráulica (entre 0,70 e 0,94 m/dia) e níveis rasos de água (entre 0,31 a 2,76 m) da Formação Barreiras ao norte da área, e (3) área de descarga de água subterrânea na Lagoa Feia, onde os níveis de água são muito rasos (entre 0,31 a 1,84 m).

Essa classificação diferenciada do método AVI, com índices de vulnerabilidade extrema, é facilmente entendida ao se analisarem os mapas intermediários (de distribuição espacial de nível de água e de valores de condutividade hidráulica). Nos demais métodos, a atribuição de pesos subjetivos para as diferentes litologias no método GOD e DRASTIC, principalmente para a Formação Barreiras (sedimentos arenosos e argilosos), e do solo sobreposto, reduziram os valores do índice para moderado.

No método AVI, o nível de água e o valor de condutividade hidráulica foram determinantes para a obtenção de valores extremamente 
baixos de resistividade hidráulica, tanto na Formação Barreiras (constituída por sedimentos menos permeáveis) quanto nos sedimentos permeáveis e inconsolidados do Quaternário. Já nos outros métodos, as características qualitativas do solo, recarga e tipos de solo foram determinantes para a classificação do índice moderado na Formação Barreiras e alto no restante da área.

Deste modo, o método AVI torna-se menos subjetivo do que os demais métodos, pois a resistência hidráulica (C) é função de variáveis quantitativas, determinadas por ensaios e medições em campo.

Independentemente dos métodos utilizados, a região apresenta uma grande sensibilidade à contaminação das águas subterrâneas, com classificações que variam de Alta a Extremamente alta, ou Moderada a Extremamente alta (nos demais métodos). Essa sensibilidade decorre da existência principalmente de formações de elevada permeabilidade (sedimentos inconsolidados) e proximidade do nível de água (freático) à superfície, por se situar no delta do rio Paraíba do Sul.

Ainda, a situação de influência-efluência do rio Paraíba do Sul na Baixada Campista também serve de alerta para se promoverem estudos relativos à qualidade das águas subterrâneas e à contribuição das águas do rio como potencial de risco para poluição das águas subterrâneas.

Há casos de contaminação das águas subterrâneas por salinização na região próxima à Lagoa Feia, que necessita de maiores estudos.

Os mapas produzidos mostraram um cenário da situação ambiental da região, com ênfase no recurso hídrico subterrâneo, fornecendo subsídios para uma elaboração de políticas públicas para preservação, proteção e uso racional desse manancial.

Por fim, acredita-se que este trabalho possa orientar futuras pesquisas ambientais, como também fornecer bases para o gerenciamento dos recursos hídricos na região.

\section{Referências}

ALLER, L. et al. DRASTIC: a standardized system for evaluating groundwater pollution potential using hydrogeologic settings. 1987. (U.S. EPA Report 600/2-85/018).

ALVES, M.G.; RAMOS, I.S.; CORIDOLA, R. Metodologia DRASTIC na análise de vulnerabilidade dos aqüíferos livres de Campos dos Goytacazes. In: XIV Simpósio Brasileiro de Sensoriamento Remoto, 2009, Natal. Anais... INPE, p. 3433-3438, 2009.

CAETANO, L.C. Água Subterrânea no Município de Campos dos Goytacazes: uma opção para o abastecimento. Dissertação (Mestrado em Ciências). Universidade Estadual de Campinas, Campinas, 2000

CORIDOLA, R. etal. Uso das técnicas de geoprocessamento na elaboração de mapa preliminar de vulnerabilidade dos aqüíferos do Município de Campos de Goytacazes - RJ. In: XIV Simpósio Brasileiro de Sensoriamento Remoto, 2005, Goiânia. Anais... INPE, p. 2933-2940, 2005.

EASTMAN, J.R. IDRISI for Windows User Guide. Universidad de Clark. Worcester, MA, USA, 1995.

FONSECA, M.J.G. Mapa geológico do estado do Rio de Janeiro. Rio de Janeiro: DNPM, 1998.

FOSTER, S.; HIRATA, R. Groundwater pollution risk evaluation: the methodology using available data. Lima: CEPIS-PAHO/WHO, 1988.

FREITAS, D.M. Águas Subterrâneas na Baixada Campista (Campos dos Goytacazes, RJ): Geometria, Qualidade e Dinâmica do Aqüifero Quaternário Deltaico. Dissertação (Mestrado em Geociências). Universidade Estadual de Campinas, Campinas, 2003.

FUNDAÇÃO CENTRO DE INFORMAÇÕES E DADOS DO RIO DE JANEIRO (CIDE). Território. Rio de Janeiro, Rio de Janeiro, 1997.
GAMA JR., E.G. Sistemas Deposicionais e Modelo de Sedimentação das Formações Campos e Emborê, Bacia de Campos, Rio de Janeiro, Brasil. Tese (Doutorado em Geociências). Universidade de São Paulo, São Paulo, 2v. 1977.

LAMEGO, A.R. Geologia das Quadrículas de Campos, São Tomé, Lagoa Feia e Xexé. Boletim 154 DNPM. Rio de Janeiro, 1955.

MARTIN, L. et al. Geologia do Quaternário costeiro do Litoral Norte do rio de Janeiro e do Espírito Santo. Belo Horizonte: CPRM, 1997.

OLIVEIRA, J.B. Pedologia aplicada. Jaboticabal: FUNEP, 2001.

PROJETO DE IRRIGAÇÃO E DRENAGEM DA CANA-DE-AÇÚCAR NA REGIÃO NORTE-FLUMINENSE (PROJIR). Síntese dos Estudos Básicos. Relatório Técnico Final. Volume 1.. 1983.

SANTOS, M.G. Mapeamento da vulnerabilidade e risco de poluição das águas subterrâneas dos Sistemas Aqüiferos Sedimentares da Região de Campos dos Goytacazes - RJ. Dissertação (Mestrado em Geociências). Universidade Estadual de Campinas, Campinas, 2004.

SILVA, C.G. Estudo da Evolução Geológica e Geomorfológica da Região da Lagoa Feia, RJ. Dissertação (Mestrado em Geologia). Universidade Federal Fluminense, Rio de Janeiro, 1987.

VAN STEMPVOORT, D.; EWERT, L.; WASSENAAR, L. AVI: A Method for Groundwater Protection Mapping in the Prairie Provinces of Canada. PPWD pilot project, Sept. 1991 - March 1992. Groundwater and Contaminants Project, Environmental Sciences Division, National Hydrology Research Institute, Saskatoon, 1992. 